\title{
Pulsed electromagnetic wave exposure induces ultrastructural damage and upregulated expression of heat shock protein 70 in the rat adenohypophysis
}

\author{
KANG CHENG $^{1 *}$, DONG-QING REN ${ }^{2 *}, \mathrm{JUN} \mathrm{YI}^{3}$, XIAO-GUANG ZHOU ${ }^{4}$, WEN-QING YANG ${ }^{5}$, \\ YONG-BIN CHEN ${ }^{2}$, YONG-QIANG LI ${ }^{6}$, XIAO-FENG HUANG ${ }^{6}$ and GUI-YING ZENG ${ }^{2}$
}

\begin{abstract}
${ }^{1}$ Department of Cardiology, Xijing Hospital, Fourth Military Medical University; ${ }^{2}$ Department of Radiation Medicine and the Ministry of Education Key Lab of Hazard Assessment and Control in Special Operational Environment, School of Public Health, Fourth Military Medical University; ${ }^{3}$ Department of Endocrine Surgery, Xijing Hospital, Fourth Military Medical University, Xi'an, Shaanxi 710032; ${ }^{4}$ Department of Urology, Bayi Children's Hospital Affiliated to People's Liberation Army General Hospital, Beijing 100700; ${ }^{5}$ Lintong Sanatorium of Chinese PLA Lanzhou Command, Xi'an, Shaanxi 710600; ${ }^{6}$ Electron Microscopy Center, Faculty of Preclinical Medicine, Fourth Military Medical University, Xi'an, Shaanxi 710032, P.R. China
\end{abstract}

Received October 23, 2013; Accepted September 4, 2014

DOI: $10.3892 / \mathrm{mmr} .2015 .3627$

\begin{abstract}
The aim of the present study was to investigate the ultrastructural damage and the expression of heat shock protein 70 (HSP70) in the rat adenohypophysis following pulsed electromagnetic wave (PEMW) exposure. The rats were randomly divided into four groups: Sham PEMW exposure, $1 \times 10^{4}$ pulses of PEMW exposure, $1 \times 10^{5}$ pulses of PEMW exposure and $3 \times 10^{5}$ pulses of PEMW exposure. Whole body radiation of $1 \times 10^{4}$ pulses, $1 \times 10^{5}$ pulses and $3 \times 10^{5}$ pulses of PEMW were delivered with a field strength of $100 \mathrm{kV} / \mathrm{m}$. The rats in each group ( $n=6$ in each) were sacrificed 12, 24, 48 and $96 \mathrm{~h}$ after PEMW exposure. Transmission electron microscopy was then used to detect the ultrastructural changes and immunocytochemistry was used to examine the expression of HSP70. Cellular damage, including mitochondrial vacuolation occurred as early as $12 \mathrm{~h}$ after PEMW exposure.
\end{abstract}

Correspondence to: Professor Xiao-Feng Huang, Electron Microscopy Center, Faculty of Preclinical Medicine, Fourth Military Medical University, 169 Changle Western Road, Xi'an, Shaanxi 710032, P.R. China

E-mail: huangxf@fmmu.edu.cn

Professor Gui-Ying Zeng, Department of Radiation Medicine and the Ministry of Education Key Lab of Hazard Assessment and Control in Special Operational Environment, School of Public Health, Fourth Military Medical University, 169 Changle Western Road, Xi'an, Shaanxi 710032, P.R. China

E-mail: gyzeng@fmmu.edu.cn

*Contributed equally

Key words: pulsed electromagnetic wave, pituitary gland, ultrastructure, heat shock protein 70, adenohypophysis
More severe cellular damages, including cell degeneration and necrosis, occurred 24 and $48 \mathrm{~h}$ after PEMW exposure. The PEMW-induced cellular damage increased as the number of PEMW pulses increased. In addition, the expression of HSP70 significantly increased following PEMW exposure and peaked after $12 \mathrm{~h}$. These findings suggested that PEMW induced ultrastructural damages in the rat adenohypophysis and that HSP70 may have contributed to the PEMW-induced adenohypophyseal damage.

\section{Introduction}

With the increased use of electronic appliances in daily life and in industrial applications, the electromagnetic radiation from electronic appliances has become a major source of environmental pollution (1). In addition, the use of the electromagnetic pulse bomb (EPB) has raised health concerns, including the health protection of employees working with EPB and electromagnetic pollution in areas exposed to EPB (2). Pulsed electromagnetic waves (PEMW) are nanosecond and subnanosecond high-voltage pulses (3). It has been observed that PEMW have various effects on biological systems (4-12). The effects of PEMW on biological systems are determined by the amplitude or field strength and the pulse width and the effects of PEMW on cells are nonlinear, transient and unstable (13). The endocrine system is one of the most EMW-sensitive systems $(5,6,12,14,15)$ and, as one of the most important endocrine organs, the pituitary gland is essential for physiological functions in humans. However, the effect of PEMW on the pituitary gland remains to be elucidated.

The pituitary gland is important in the growth, development and normal physiological functions of the body due to its secretion of several hormones (16). There are five types of endocrine cell, including somatotrophs, lactotrophs, corticotrophs, gonadotrophs and thyrotrophs, which secrete seven 
hormones regulating their targets, the thyroid gland, adrenal glands and gonads (16). Therefore, damage to the pituitary can affect the normal functions of the body, thus leading to pathological abnormalities. However, morphological changes, particularly ultrastructural changes, in the pituitary following PEMW exposure remain to be elucidated.

In the present study, the ultrastructural changes and the expression of HSP70 was investigated in the adenohypophysis (the anterior pituitary) from rats receiving $1 \times 10^{4}, 1 \times 10^{5}$ and $3 \times 10^{5}$ pulses of PEMW with a field strength of $100 \mathrm{kV} / \mathrm{m}$.

\section{Materials and methods}

Animals and irradiation. All animal experimental procedures were approved by the Committee for Animal Experiments at The Fourth Military Medical University (Xi'an, China). Six-week-old male Sprague Dawley rats (weighing 200 \pm 20 g) were used in the present study. All animals were obtained from the Animal Center at the Fourth Military Medical University. The rats were housed at $20-25^{\circ} \mathrm{C}$ and $40-60 \%$ relative humidity and were maintained with food and water ad libitum for 1 week prior to PEMW exposure.

The rats were randomly divided into four groups: PEMW sham exposure group and groups receiving $1 \times 10^{4}, 1 \times 10^{5}$ and $3 \times 10^{5}$ pulses of PEMW exposure. Each group contained 24 rats. The 24 rats in each group were sacrificed 12, 24, 48 and $96 \mathrm{~h}$ ( $\mathrm{n}=6$ in each) after PEMW exposure. The rats were placed into a plexiglass cage (Wuxi Jiarunfeng Science and Technology Co., Ltd, Jiangsu, China), where the rats were comfortably housed. The exposure cage was placed seven meters from the radiation source. Whole body radiation of $1 \times 10^{4}, 1 \times 10^{5}$ and $3 \times 10^{5}$ pulses of PEMW were delivered with a field strength of $100 \mathrm{kV} / \mathrm{m}$. For the PEMW sham exposure group, the rats were treated under the same conditions, but without PEMF exposure.

Tissue preparation. The rats were anesthetized with $1 \%$ sodium pentobarbital $(50 \mathrm{mg} / \mathrm{kg}$; Sigma-Aldrich, Shanghai, China) 12, 24, 48 and $96 \mathrm{~h}$ after PEMW exposure and were transcardially perfused with ice-cold $4 \%$ paraformaldehyde for $1 \mathrm{~h}$. For electron microscopy, the pituitary tissues were excised and cut into $1 \mathrm{~mm}^{3}$ blocks. The blocks were fixed with $3 \%$ glutaraldehyde and post-fixed with $1 \%$ osmium tetroxide, followed by washing in $0.1 \mathrm{~mol} / 1$ phosphate-buffered saline (PBS; pH 7.6). The blocks were dehydrated using graded concentrations of acetone, filtered with acetone and embedding medium (Sigma-Aldrich) and then embedded in epoxy resin. Ultrathin sections $(70 \mathrm{~nm})$ were obtained using a Leica Ultracut UCT microtome (Leica, Mannheim, Germany). The sections were viewed using a JEOL JEM 1400 transmission electron microscope equipped with a Gatan ORIUS ${ }^{\mathrm{TM}}$ TEM CCD camera (Nippon Gatan, Tokyo, Japan). For immunocytochemistry, the pituitary tissues were excised and soaked in $20 \%$ sucrose in PBS at $4^{\circ} \mathrm{C}$ overnight. Sections $(15 \mu \mathrm{m})$ were obtained using a Leica CM3050S cryostat (Leica) and were stored at $-20^{\circ} \mathrm{C}$ for subsequent immunocytochemical analysis.

Immunocytochemistry. Sections $(15 \mu \mathrm{m})$ were washed in $0.1 \mathrm{M}$ PBS and treated with $0.3 \%$ hydrogen peroxide in $100 \%$ methanol for $30 \mathrm{~min}$ at room temperature, followed by washing with PBS. The sections were blocked using $5 \%$ bovine serum albumin for $20 \mathrm{~min}$ at room temperature and then incubated with primary antibodies against HSP70 (rabbit anti-rat antibodies; 1:200; Abcam, Shanghai, China) overnight at $4^{\circ} \mathrm{C}$. The primary antibody was then washed three times using PBS for $5 \mathrm{~min}$ and biotinalyted goat anti-rabbit immunoglobulin G (Vector Laboratories, Inc., Burlingame, CA, USA) was applied for $20 \mathrm{~min}$ at room temperature and was then reacted with horseradish peroxidase conjugated streptavidin (Vector Laboratories, Inc.) for $2 \mathrm{~h}$. The sections were then developed using diaminobenzidine (Sigma-Aldrich) and were mounted onto gelatinized glass slides, which were dehydrated using graded ethanol solutions prior to mounting under coverslips. Sections, in which the primary antibodies were omitted, were used as negative controls.

Five sections were selected from each rat. The distal section of the pituitary gland was divided into four regions (Fig. 1), as previously reported (17). Since region A, adjacent to the neurohypophysis, was easily located under a light microscope, three fields were randomly selected, without overlaps, in region A at low magnification (x10) for each section. At high magnification (x40), the immunopositive cells in region A were counted and the percentage of positive cells and intensity of immunoreactivity were analyzed using Leica Quantimet quantitative analysis software (570C; Leica).

Statistical analysis. All statistical analyses were performed using SPSS 11.0 (SPSS, Inc., Chicago, IL, USA). The values are expressed as the mean \pm standard deviation. One-way analysis of variance was used to compare the differences among the groups. $\mathrm{P}<0.05$ was considered to indicate a statistically significant difference.

\section{Results}

Ultrastructural changes induced by PEMW. PEMW did not induce any clear morphological changes in the pituitary cells, stromal cells or their surrounding tissues when examined under a light microscope. Therefore, electron microscopy was used in the present study to investigate the ultrastructure of pituitary glands in rats treated with PEMW. Based on the characteristic cellular morphology and the distinguished size and morphology of secretory granules in the adenohypophysis, the somatotrophs, lactotrophs, corticotrophs, gonadotrophs and thyrotrophs were distinguished from each other using electron microscopy. In the PEMW sham exposure group, no changes in the intracellular organelles or secretory granules in these cells were identified in the adenohypophysis. By contrast, PEMW exposure induced ultrastructural damage in the adenohypophysis from rats following $3 \times 10^{5}$ pulse PEMW exposure (Fig. 2). After $12 \mathrm{~h}$ exposure, intercellular gaps between the pituitary cells and their surrounding tissues were increased and capillary congestion was evident. Swollen mitochondria with enlarged and broken cristae were found in the somatotrophs (Fig. 2A) and vacuolated mitochondria with broken cristae were frequently observed in the corticotrophs (Fig. 2B). Similar ultrastructural abnormalities in the mitochondria, were also observed in other types of pituitary cell, although to a lesser extent. 
Table I. Heat shock protein 70 immunoreactivity following $3 \times 10^{5}$ pulses of pulsed electromagnetic wave exposure.

\begin{tabular}{lcc}
$\begin{array}{l}\text { Time (h) } \\
\text { following } \\
\text { exposure }\end{array}$ & $\begin{array}{c}\text { Immunopositive } \\
\text { cells }(\%)\end{array}$ & $\begin{array}{c}\text { Immunoreactivity } \\
\text { intensity }\end{array}$ \\
\hline 0 & $0.02 \pm 0.00$ & $164.67 \pm 1.42$ \\
12 & $0.49 \pm 0.15^{\mathrm{a}}$ & $184.50 \pm 21.74^{\mathrm{a}}$ \\
24 & $0.16 \pm 0.08^{\mathrm{ab}}$ & $175.90 \pm 5.76$ \\
48 & $0.14 \pm 0.04^{\mathrm{ab}}$ & $169.77 \pm 4.01$ \\
96 & $0.08 \pm 0.04^{\mathrm{b}}$ & $173.57 \pm 1.72$ \\
\hline
\end{tabular}

${ }^{\mathrm{a}} \mathrm{P}<0.05$, vs. control; ${ }^{\mathrm{b}} \mathrm{P}<0.01$, vs. $12 \mathrm{~h} ; \mathrm{n}=6$ in each group.

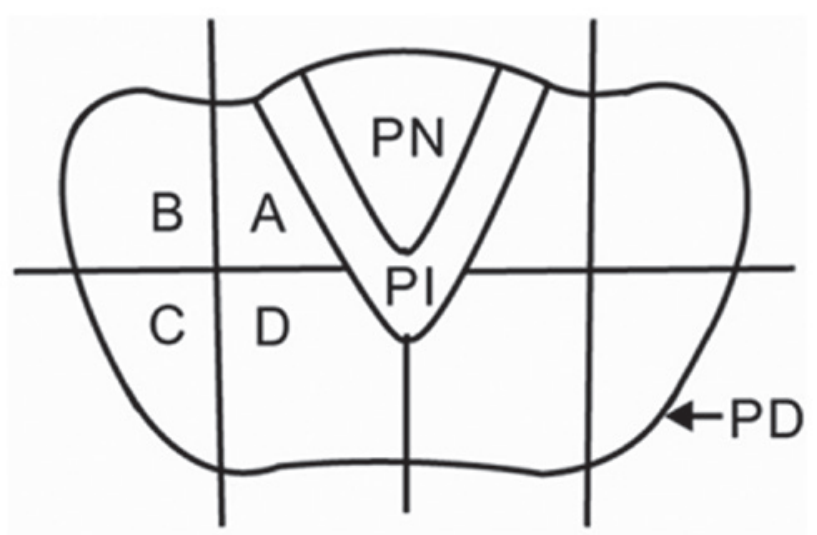

Figure 1. Schematic of the structure of the rat pituitary. The pars distalis (PD) was divided into areas A-D. PN, neurohypophysis; PI, intermediate lobe.

After $24 \mathrm{~h}$ PEMW exposure, there was frequent depletion of secretory granules in the cells. Vacuolated mitochondria with abnormal membranous structure and enlarged rough endoplasmic reticulum (RER) were observed in the lactotrophs (Fig. 2C). Swollen mitochondria, vacuolated mitochondria with a myelin-like structure, which had the appearance of a concentric circle, were also found in mitochondria in the gonadotrophs (Fig. 2D). In addition, enlarged Golgi complexes were present in the somatotrophs and vacuolated mitochondria with broken cristae were observed in the corticotrophs and thyrotrophs.

After $48 \mathrm{~h}$ PEMW exposure, marked infiltration of inflammatory cells and severe cell swelling were identified in the pituitary tissue. Bulky heterochromatins were accumulated close to the nuclear membrane in the somatotrophs (Fig. 2E) and myelin-like structures in the mitochondria and enlarged Golgi complexes were observed in the lactotrophs (Fig. 2F). In addition, enlarged and dilated RER were present in the gonadotrophs. Cell degeneration, pyknosis and increased intracellular gaps were also found in the thyrotrophs and more vacuolated mitochondria were found in the corticotrophs.

After $96 \mathrm{~h}$ PEMW exposure, interstitial edema and vascular congestion remained, however the morphology of the cells in the adenohypophysis had recovered almost to normal.

The present study also investigated ultrastructural changes in the adenohypophysis $24 \mathrm{~h}$ after $1 \times 10^{4}, 1 \times 10^{5}$ and $3 \times 10^{5}$ pulses of PEMW. After $24 \mathrm{~h}$ following the $1 \times 10^{4}$ pulses of PEMW exposure, mild injury to the vascular endothelia and platelet aggregation was observed. A depletion in secretory granules and enlarged RER were observed in a number of lactotrophs (Fig. 2G) and mild enlargement of RER and mitochondrial vacuolation had occurred in the somatotrophs (Fig. $2 \mathrm{H}$ ). After $24 \mathrm{~h}$ following the $1 \times 10^{5}$ pulses of PEMW exposure, mitochondrial swelling and vacuolation was more prevalent in these pituitary cells. Clearly enlarged RER and vacuolated mitochondria were observed in the somatotrophs and thyrotrophs. Accumulation of heterochromatins close to the nuclear membrane was observed in the somatotrophs (Fig. 2I) and increased Golgi vesicles were identified in the thyrotrophs (Fig. 2J). In addition, enlarged RER and vacuolated mitochondria were also found in the somatotrophs and thyrotrophs. After $24 \mathrm{~h}$ following the $3 \times 10^{5}$ pulses of PEMW exposure, more severe ultrastructural damage was observed in the pituitary cells. Marked inflammatory cell infiltration and severe cell swelling were identified and mitochondrial swelling and vacuolation was observed throughout the cells. Disruption of the mitochondrial membrane was observed in the lactotrophs (Fig. 2C) and in the gonadotrophs (Fig. 2D).

Expression of HSP70 following PEMW exposure. The present study further investigated the expression of the HSP70 protein 12, 24, 48 and $96 \mathrm{~h}$ after $3 \times 10^{5}$ pulses of PEMW exposure using immunocytochemistry. In the sham exposure group, HSP70 immunopositive cells were diffusely distributed with a weak brownish staining in the cytoplasm and little nuclear immunoreactivity was observed (Fig. 3A). After1 $2 \mathrm{~h}$ following the $3 \times 10^{5}$ pulses of PEMW exposure, the percentage of HSP70 immunopositive cells was significantly increased $(\mathrm{P}<0.01)$ and the intensity of the immunoreactivity was increased significantly $(\mathrm{P}<0.05)$ compared with the PEMW sham exposure group (Table I). The majority of the immunoreactivity was observed in the nuclei, which exhibited dark staining (Fig. 3B). The nuclear immunoreactivity started to decrease $24 \mathrm{~h}$ after $3 \times 10^{5}$ pulses of PEMW exposure and remained at a significantly higher level $48 \mathrm{~h}$ after $3 \times 10^{5}$ pulses of PEMW exposure (Fig. 3C). The percentage of HSP70 immunopositive cells were significantly higher and the intensity of the immunoreactivity was increased significantly 24 and $48 \mathrm{~h}$ after $3 \times 10^{5}$ pulses of PEMW exposure compared with the sham exposure group (Table I). After $96 \mathrm{~h}$ following $3 \times 10^{5}$ pulses of PEMW exposure, the percentage of immunopositive cells decreased significantly, however it remained higher compared with the that in the sham control group (Fig. 3D). The percentage of HSP70 immunopositive cells were significantly lower 24, 48 and $96 \mathrm{~h}$ after $3 \times 10^{5}$ pulses of PEMW exposure compared with that observed $12 \mathrm{~h}$ after $3 \times 10^{5}$ pulses of PEMW exposure $(\mathrm{P}<0.01$; Table I).

\section{Discussion}

In the present study, ultrastructural changes in the adenohypophysis from rats receiving $1 \times 10^{4}, 1 \times 10^{5}$ and $3 \times 10^{5}$ pulses of PEMW, were investigated using transmission electron microscopy. The results revealed that PEMW induced adenohypophysal damage in the mitochondria, endoplasmic reticulum (ER) and chromatin. PEMW with a higher number 

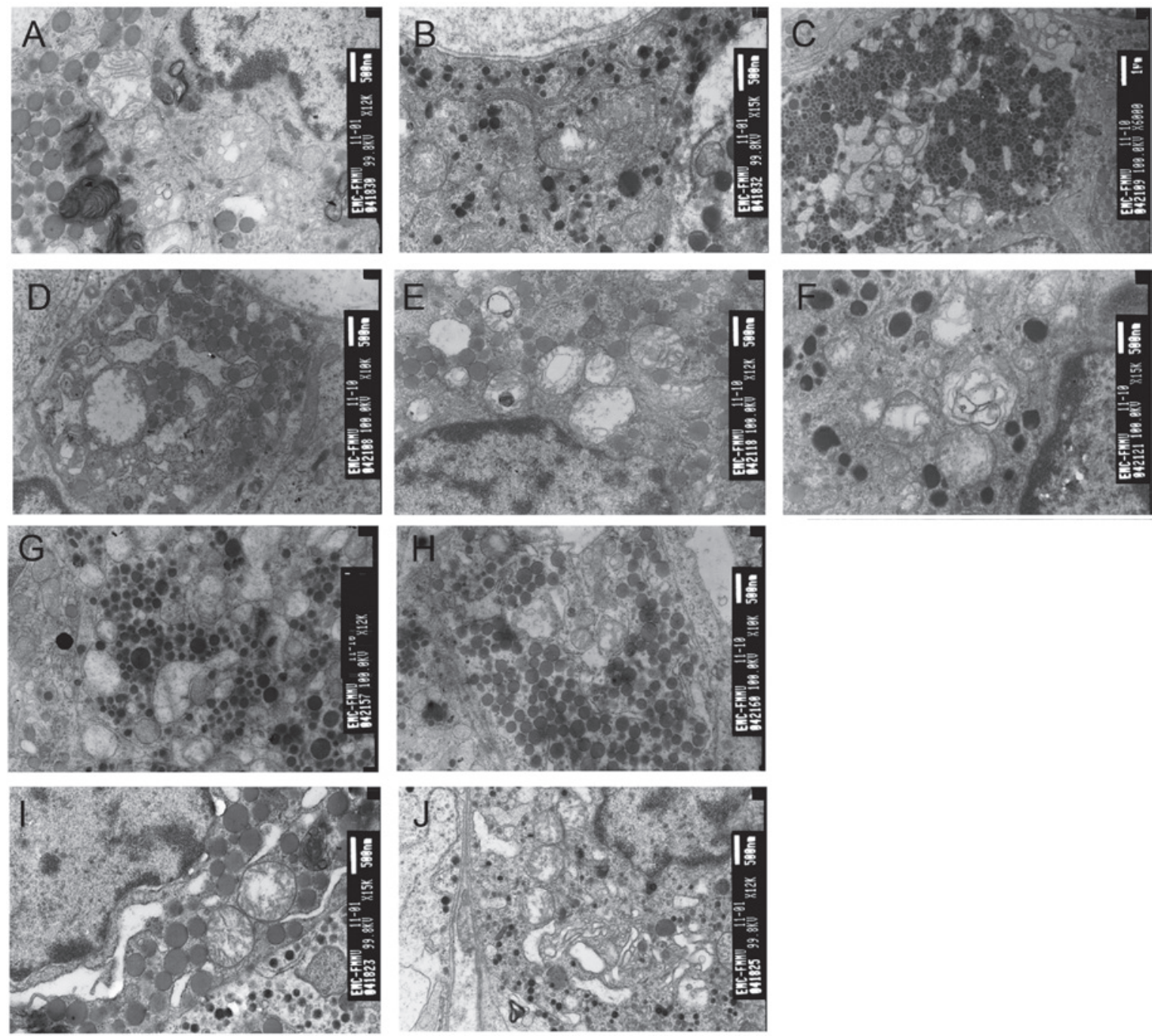

Figure 2. Pulsed electromagnetic wave (PEMW) induces ultrastructural damage in the adenohypophysis. (A) Electron micrograph of a somatotroph $12 \mathrm{~h}$ after $3 \times 10^{5}$ pulses of PEMW exposure, exhibiting swollen mitochondria with enlarged and broken cristae, vacuolated mitochondria, myelin-like structure in the mitochondria and chromatin aggregation at the periphery of the nuclear membrane (magnification, $\mathrm{x} 12,000)$ ). (B) Electron micrograph of a corticotroph $12 \mathrm{~h}$ after $3 \times 10^{5}$ pulses of PEMW exposure exhibiting vacuolated mitochondria with enlarged and broken cristae (magnification, x15,000). (C) Electron micrograph of a lactotroph $24 \mathrm{~h}$ after $3 \times 10^{5}$ pulses of PEMW exposure exhibiting severe vacuolation in the mitochondria with broken and fused membrane and the enlargement of ER (magnification, x6,000). (D) Electron micrograph of a gonadotroph $24 \mathrm{~h}$ after $3 \times 10^{5}$ pulses of PEMW exposure exhibiting cell edema, vacuolation in the mitochondria with a dissolved membrane and enlargement of the ER (magnification, x10,000). (E) Electron micrograph of a somatotroph $48 \mathrm{~h}$ after $3 \times 10^{5}$ pulses of PEMW exposure exhibiting myelin-like structure in the mitochondria, broken cristae in certain mitochondria and bulky heterochromatin accumulated close to the nuclear membrane (magnification, x12,000). (F) Electron micrograph of a lactotroph $48 \mathrm{~h}$ after 3x10 $0^{5}$ pulses of PEMW exposure exhibiting myelin-like structure in the mitochondria (magnification, x15,000). (G) Electron micrograph of a lactotroph $24 \mathrm{~h}$ after $1 \times 10^{4}$ pulses of PEMW exposure exhibiting complete depletion of secretory granules, partial depletion of secretory granules and enlargement of ER (magnification, x12,000). (H) Electron micrograph of a somatotroph $24 \mathrm{~h}$ after $1 \times 10^{4}$ pulses of PEMW exposure exhibiting enlargement of ER and vacuolation in the mitochondria (magnification, x10,000). (I) Electron micrograph of a somatotroph $24 \mathrm{~h}$ after $1 \times 10^{5}$ pulses of PEMW exposure exhibiting enlargement of ER, vacuolation in the mitochondria and chromatin aggregation at the periphery of the nuclear membrane (magnification, x15,000). (J) Electron micrograph of a thyrotroph $24 \mathrm{~h}$ after $1 \times 10^{5}$ pulses of PEMW exposure exhibiting enlargement of ER, increased Golgi vesicles and vacuolation in the mitochondria (x12,000). ER, endoplasmic reticulum.

of pulses produced more severe damage in the adenohypophysis compared with the PEWM with a lower pulse. In addition, the expression of HSP70 was increased significantly following PEMW exposure and reached its peak $12 \mathrm{~h}$ following PEMW exposure. Since the HSP70 protein is upregulated in response to stress stimuli (18), the findings of the present study suggests that PEMW-induced cellular damage may be associated with the cellular response to the stress induced by PEMW.

In the present study, the effects of PEMW on ultrastructural changes in the pituitary were investigated $12,24,48$ and $96 \mathrm{~h}$ after PEMW exposure. The results revealed that cellular damage, including cellular edema and mitochondrial vacuolation occurred as early as $12 \mathrm{~h}$ after PEMW exposure. More severe cellular damages, including the depletion of secretory granules, ER and Golgi complex enlargement, accumulation of heterochromatins close to the nuclear membrane and myelin-like structure of mitochondria, occurred $24 \mathrm{~h}$ after PEMW exposure, suggesting that PEMW induced cell degeneration and necrosis. The PEMW-induced cell degeneration and necrosis was aggravated $48 \mathrm{~h}$ after PEMW exposure and an increase in intercellular gaps also occurred. In addition, the PEMW-induced cellular damage increased as the pulse time of the PEMW increased, particularly in the somatotrophs and lactotrophs. This finding was consistent with those of previous 


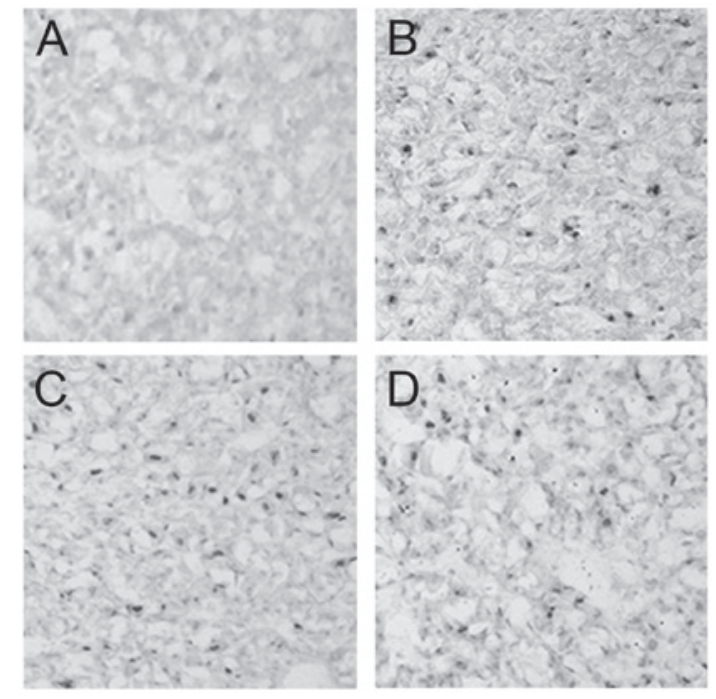

Figure 3. Immunocytochemical expression of heat shock protein 70 in the (A) PEMW sham exposure group and the groups (B) 12 , (C) 48 and (D) $96 \mathrm{~h}$ after $3 \times 10^{5}$ pulses of PEMW exposure. (Magnification, x400). PEMW, pulsed electromagnetic wave.

studies that showed that EMP exposure induced cellular damage in the pituitary $(5,6)$. However, the degree of cellular damage differed among these studies, possibly due to differences in the pulse time and field strength used, suggesting that PEMW-induced cellular damage may be associated with the pulse time and the field strength of PEMW.

The occurrence and development of cellular damage can be caused by several mechanisms, including deficiency in intracellular adenosine triphosphate (ATP), damage of the cell membrane, increase in free intracellular calcium and irreversible mitochondrial damage (19). Several studies using atomic force microscopy have demonstrated that electromagnetic pulses induce cell membrane perforation in cultured pituitary cells, hypothalamic neurons and hippocampal neurons (20-22). In addition, it has been observed that high power microwaves induce an increase in free intracellular calcium and a decrease in the mitochondrial membrane potential in hypothalamic neurons $6 \mathrm{~h}$ after exposure (9). Therefore, the PEMW-induced ultrastructural changes that were observed in the adenohypophysis in the present study may have been caused by cell membrane perforation, an increase in free intracellular calcium and a decrease in mitochondrial membrane potential, thus leading to a change in the selectivity and permeability of the mitochondrial membrane. Mitochondria are the sites of ATP synthesis in the cell and mitochondrial dysfunction results in a deficiency in intracellular ATP, which can lead to the malfunction of ion pumps in the cell membrane, cellular edema, enlargement of ER and eventual cell death (23).

The upregulation of HSP is a main feature of the stress response, which is conserved in prokaryotes and eukaryotes, as a protection from harmful stimuli (18). It has been demonstrated that pulsed microwaves, a harmful environmental stimuli, induce a stress response in rats and increase the synthesis of HSP in Escherichia coli cells $(24,25)$. HSP70, a member of the HSP superfamily, is abundantly expressed in the majority of species and is markedly induced by cellular stress (26). HSP70 is important in the maintenance of protein stability, improvement of cellular tolerance to stress stimuli and maintenance of normal physiological functions in the cell $(27,28)$. There are two isoforms of the HSP70 protein, the constitutive isoform and the stress-inducible isoform (29). The constitutive isoform of HSP70 is expressed mainly in the cytoplasm in the absence of stress and can be moderately upregulated during stress. By contrast, the stress-inducible isoform of HSP70 is generally not expressed in unstressed cells and is highly inducible under conditions of stress. In addition, the HSP70 protein translocates from the cytoplasm to the nucleus in response to stress and translocates from the nucleus to the cytoplasm in the absence of stress, in a temperature independent manner (30).

The present study also examined the effects of PEMW on the expression of HSP70 in the pituitary 12, 24, 48 and $96 \mathrm{~h}$ after PEMW exposure. In the PEMW sham exposure group, weak brownish staining was observed in the cytoplasm and minimal nuclear immunoreactivity was observed in the HSP70 immunopositive cells, suggesting that the constitutive isoform of HSP70 is expressed mainly in the absence of stress in the adenohypophysis. By contrast, $12 \mathrm{~h}$ after $3 \times 10^{5}$ pulses of PEMW exposure, the percentage of HSP70 immunopositive cells were significantly increased and the immunoreactivity, with dark brown staining, was predominantly observed in the nucleus, suggesting that the stress-inducible isoform of HSP70 was expressed mainly in the pituitary following PEMW exposure. The nuclear immunoreactivity began to decline $24 \mathrm{~h}$ after PEMW exposure, suggesting that the synthesis of the inducible isoform of HSP70 had decreased. The expression of HSP70 remained higher compared with the control $96 \mathrm{~h}$ after PEMW exposure, although to a lesser degree. The PEMW-induced increase in the expression of HSP70 occurred earlier than the PEMW-induced ultrastructural changes in the pituitary, suggesting that PEMW-induced cellular damage may be associated with the cellular stress induced by PEMW. It has been observed that radiofrequency radiation and pulsed microwaves induce mitochondrial DNA damage and cell injury through oxidative stress $(31,32)$. Therefore, the HSP70-mediated stress response may have contributed to the PEMW-induced ultrastructural damage in the pituitary. 
In conclusion, the present study demonstrated that PEMW induced ultrastructural damage and the overexpression of HSP70 in the nuclei in the adenohypophysis. Somatotrophs and lactotrophs were the most sensitive cells to PEMW exposure and the mitochondria and RER were observed as the organelles most sensitive to the PEMW exposure. The PEMW-induced adenohypophyseal damage was time-dependent and was determined by the pulse of PEMW. HSP70 may have contributed to the PEMW-induced adenohypophyseal damage.

\section{Acknowledgements}

This study was supported by the Program for Changjiang Scholars and Innovative Research Team in University and the Research Fund of National Natural Science Foundation (nos. 30570447, 30901215 and 81172636, respectively).

\section{References}

1. Dämvik M and Johansson O: Health risk assessment of electromagnetic fields: a conflict between the precautionary principle and environmental medicine methodology. Rev Environ Health, 25: 325-333, 2010.

2. Schwartau W: Information Warfare - Cyberterroism: Protecting Your Personal Security in the Electronic Age.Thunder's Mouth Press, New York, NY, 1996. Available from: http://www. infowar.com.

3. Minamitani Y, Ohe Y, Ueno T and Higashiyama Y: Output characteristics of high power pulsed electromagnetic wave generator for medical applications using water capacitor and water gap switch. Pulsed Power Conference, 2007 16th IEEE International 2: 1240-1243, 17-22 June 2007.

4. Ding GR, Li KC, Wang XW, Zhou YC, Qiu LB, Tan J, Xu SL and Guo GZ: Effect of electromagnetic pulse exposure on brain micro vascular permeability in rats. Biomed Environ Sci 22: 265-268, 2009

5. Fang H, Zeng G, Ren D and Jin C, Huang X and Guo Z: Study on ultrastructural changes of the pituitary gland in rats exposed to pulsed electromagnetic fields (PEMF). Chin J Radiol Med Prot 25: 175-177, 2005.

6. Fang HH, Zeng GY, Nie Q, Kang JB, Ren DQ, Zhou JX and $\mathrm{Li}$ YM: Effects on structure and secretion of pituitary gland in rats after electromagnetic pulse exposure. Zhonghua Yi Xue Za Zhi 90: 3231-3234, 2010 (In Chinese).

7. Li BF, Guo GZ, Ren DQ, Jing L and Zhang RB: Electromagnetic pulses induce fluctuations in blood pressure in rats. Int J Radiat Biol 83: 421-429, 2007.

8. Li KC, Ma SR, Ding GR, Guo Y and Guo GZ: Effects of electromagnetic pulse on bone metabolism of mice in vivo. Biomed Environ Sci 22: 518-521, 2009.

9. Meng L, Peng RY, Gao YB, Wang SM, Ma JJ, Hu WH, Wang DW, Su ZT, Dong B and Xu TH: Changes of apoptosis, mitochondrion membrane potential and $\mathrm{Ca}^{2+}$ of hypothalamic neurons induced by high power microwave. Zhonghua Lao Dong Wei Sheng Zhi Ye Bing Za Zhi 24: 739-741, 2006 (In Chinese).

10. Wang XW, Ding GR, Shi CH, Zhao T, Zhang J, Zeng LH and Guo GZ: Effect of electromagnetic pulse exposure on permeability of blood-testicle barrier in mice. Biomed Environ Sci 21: 218-221, 2008.

11. Yang ML, Liu HQ, Guo J, Zhang YL, Zeng LH and Guo GZ: Effects of electromagnetic pulse on the expression of GABAA receptor in hypothalamus of male offsprings of rats. Progress in Modern Biomedicine 11: 1257-1260, 2011 (In Chinese).

12. Zhou XG, Zeng GY, Ren DQ, Fang HH, Sun XM and Huang XF: Study of the ultrastructural changes in the thyroid gland of rats exposed to pulsed electromagnetic wave. J Radiat Res Radiat Process 24: 120-124, 2006.
13. Merritt JH, Kiel JL and Hurt WD: Considerations for human exposure standards for fast-rise-time high-peak-power electromagnetic pulses. Aviat Space Environ Med 66: 586-589, 1995.

14. Cao XZ, Wang DW, Zhao ML, Gao YB, Cui XM, Peng RY and Zhang YR: The study on the serum hormone level in macaques irradiated by electromagnetic pulse (EMP). Chin J Phys Med Rehabil 24: 679-682, 2002 (In Chinese).

15. Cao XZ, Wang DW, Zhao ML, Li CL, Shu T, Peng RY, Chen HY and Gao YB: A preliminary study on the effect of $99 \mathrm{~W} \cdot \mathrm{CM}-2$ high powered pulse microwave on serum hormone level in rats. J Prev Med Chin PLA 20: 8-11, 2002 (In Chinese).

16. Nussey S and Whitehead S: Endocrinology: An Integrated Approach. Oxford: BIOS Scientific Publishers, Oxford, 2001.

17. Poole MC and Kornegay WD 3rd: Cellular distribution within the rat adenohypophysis: a morphometric study. Anat Rec 204: 45-53, 1982.

18. Feige U and Polla BS: Hsp70 - a multi-gene, multi-structure, multi-function family with potential clinical applications. Experientia 50: 979-986, 1994.

19. Trump BF, Berezesky IK, Chang SH and Phelps PC: The pathways of cell death: oncosis, apoptosis, and necrosis. Toxicol Pathol 25: 82-88, 1997.

20. Cao XZ, Wang DW, Zhao ML and Zhang S: The atomic force microscope study on the pituitary cell membrane perforate induced by electromagnetic pulse. Chin J Phys Med Rehabil 25: 462-464, 2003.

21. Cao XZ, Wang DW, Zhao ML, Zhang S, Zhang DT, Zhang JG, Liu J and Zhang Y: The atomic force microscope study on the hypothalamus neuron memberane perforation induced by EMP. Bull Acad Mil Med Sci 27: 416-418, 2003.

22. Zhao ML, Cao XZ, Wang DW, Zhang S, Liu J, Zhang Y and Qian X: The Atom force microscopy study on the hypothalamus neurons membrane perforate induced by EMP. Chin J Med Phys 21: 147-149, 2004.

23. Ascah A, Khairallah M, Daussin F, Bourcier-Lucas C, Godin R, Allen BG, Petrof BJ, Des Rosiers C and Burelle Y: Stress-induced opening of the permeability transition pore in the dystrophin-deficient heart is attenuated by acute treatment with sildenafil. Am J Physiol Heart Circ Physiol 300: H144-H153, 2011.

24. Del Re B, Bersani F, Mesirca P and Giorgi G: Synthesis of DnaK and GroEL in Escherichia coli cells exposed to different magnetic field signals. Bioelectrochemistry 69: 99-103, 2006.

25. Esmekaya MA, Ozer C and Seyhan N: $900 \mathrm{MHz}$ pulse-modulated radiofrequency radiation induces oxidative stress on heart, lung, testis and liver tissues. Gen Physiol Biophys 30: 84-89, 2011.

26. Proctor CJ and Lorimer IA: Modelling the role of the Hsp70/Hsp90 system in the maintenance of protein homeostasis. PLoS One 6: e22038, 2011.

27. Gilby KL, Armstrong JN, Currie RW and Robertson HA: The effects of hypoxia-ischemia on expression of c-Fos, c-Jun and Hsp70 in the young rat hippocampus. Brain Res Mol Brain Res 48: 87-96, 1997.

28. Lindquist S and Craig EA: The heat-shock proteins. Annu Rev Genet 22: 631-677, 1988.

29. Hageman J, van Waarde MA, Zylicz A, Walerych D and Kampinga HH: The diverse members of the mammalian HSP70 machine show distinct chaperone-like activities. Biochem J 435: 127-142, 2011.

30. Finka A, Rayees U and Goloubinoff P: Meta-analysis of heatand chemically upregulated chaperone genes in plant and human cells. Cell Stress Chaperones 16: 15-31, 2010.

31. Garaj-Vrhovac V, Gajski G, Pažanin S, Sarolić A, Domijan AM, Flajs D and Peraica M: Assessment of cytogenetic damage and oxidative stress in personnel occupationally exposed to the pulsed microwave radiation of marine radar equipment. Int J Hyg Environ Health 214: 59-65, 2011.

32. Xu S, Zhou Z, Zhang L, Yu Z, Zhang W, Wang Y, Wang X, Li M, Chen Y, Chen C, He M, Zhang G and Zhong M: Exposure to $1800 \mathrm{MHz}$ radiofrequency radiation induces oxidative damage to mitochondrial DNA in primary cultured neurons. Brain Res 1311: 189-196, 2010. 